\title{
MEASURING AND ESTIMATING SHEAR FORCE OF ONE STA- PLED AND ONE-ROW MULTI STAPLED WOOD JOINTS
}

\author{
Samet Demirel ${ }^{1,}$, Gamze Kalayci ${ }^{1}$
}

\begin{abstract}
Since staple is the most used fastener in furniture frame, its holding capacity in solid wood joints is need to be known. Therefore, lateral shear resistance capacity of one stapled and one-row multi stapled joints constructed from Scotch pine, alder, and beech were investigated. Results showed that the joints constructed from beech with a density of $540 \mathrm{~kg} / \mathrm{m}^{3}$ yielded $4893 \mathrm{~N}$, the 4 staples joints constructed from alder with a density of $510 \mathrm{~kg} / \mathrm{m}^{3}$ yielded $4487 \mathrm{~N}$, and the 4 staples joints constructed from Scotch pine with a density of $450 \mathrm{~kg} / \mathrm{m}^{3}$ yielded $3498 \mathrm{~N}$. Three and two staples connected joints also indicated decreasing trend when changing wood from beech to alder and Scotch pine. Results also indicated that increasing number of staple from 2 to 4 in onerow joints increased force of the joints. Two prediction equations were derived to predict the shear of one-row multi stapled wood joints. Both equations yielded remarkable results compared to actual laboratory test results.
\end{abstract}

Keywords: Alder, beech, lateral shear, staple, Scots pine, wood joint.

\section{INTRODUCTION}

Solid wood had been used in furniture frame for centuries regardless paying attention on engineering design. However, it is rapidly becoming serious issue for using wood material in cost-effective way without waste. Especially, the engineering data concerning the lateral resistance of stapled joints is having more importance for designing and reengineering the products of furniture manufacturers to meet product strength and durability (Demirel et al. 2018).

Several fasteners have been used in furniture upholstery. Staple is one of the those fasteners (Demirel 2012), and it is driven into wood members to assemble them with an air gun. Therefore, it is fast and easy to use as a fastener in upholstered furniture frame manufacturing (Zhang and Maupin 2004, Demirel et al. 2013).

The resistance of an upholstered furniture frame predominantly depends on the fastenings that hold its structural members together (Demirel et al. 2018). Therefore, the fastener holding capacity, such as lateral shear resistances, of a material needs to be known (Demirel 2012), especially for the solid wood materials. In Figure 1, the front rail connected to front stump with staple at an angle of $45^{\circ}$ degree in a sofa frame constructed from pine. This is a good view of an arm part of sofa frame under external loads where staples are exposed to side loads (GSA 1998).

Some authors, Zhang et al. (2002a), Zhang et al. (2002b), Erdil et al. (2003), Zhang and Maupin (2004), Zhang et al. (2006) were conducted the studies on lateral and direct withdrawal load resistances of staples-only connected joints in plywood and Yadama et al. (2002), Erdil et al. (2003), Zhang et al. (2006), Demirel and Zhang (2014), Demirel et al. (2013) conducted the studies on lateral and direct withdrawal load resistances of OSB joints attached with only staple. Dai et al. (2008) studied tensile strength of glued-only joints made of pine plywood and OSB materials. However, there is lack of study on lateral and direct withdrawal load resistances of staples connected joints constructed from solid wood such as Scotch pine, beech (widely used in furniture industry), alder (becoming popular in furniture making industry). 


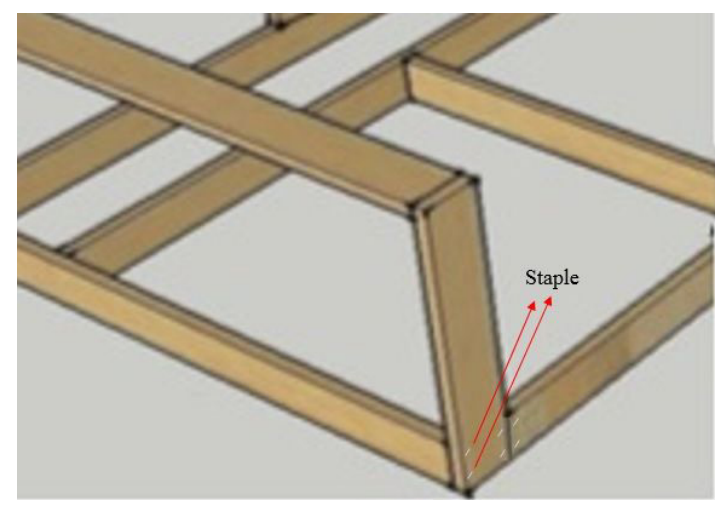

Figure 1: An example of the front rail and stump joint connected with staple.

Demirel et al. 2013 investigated the shear of single stapled and one-row multi stapled joints made of three OSBs. The overall densities of OSB-type-I, OSB-type-II, and OSB-type-III were $460 \mathrm{~kg} / \mathrm{m}^{3}, 470 \mathrm{~kg} / \mathrm{m}^{3}$ and $560 \mathrm{~kg} / \mathrm{m}^{3}$, respectively. Outputs of the study showed that the shear force of OSB-type-I joints was significantly lower than the ones of OSB-type-II and OSB-type-III joints. Increasing number of staples from two to four with one increment significantly increased the shear force of the joints. Derived two alternative prediction equations provided a possibility to estimate the shear force of OSB joints.

The objectives of this study were considering wood specie effects on the shear of one stapled joints; determining the effects of numbers of staple and wood specie on the shear of one-row multi stapled joints; quantitatively determining the effect of the numbers of staple and wood specie density on the shear resistance of the multi stapled joints in wood materials; and deriving some equations to predict the shear resistance of one-row stapled wood joints.

\section{MATERIAL AND METHODS}

\section{Materials}

The common view of a stapled furniture joint sample in this study is shown in Figure 2. One main member and one side member were the two general members consisting of each sample.

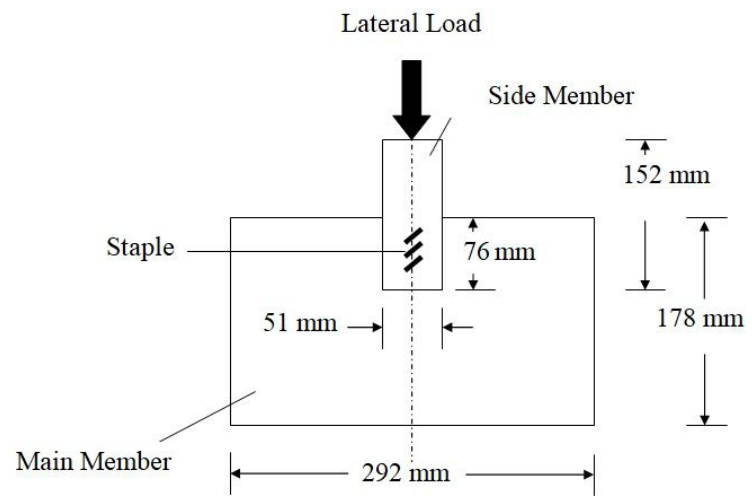

Figure 2: The general view of one-row multi-staple wood joint. 
These two members were stapled at an angle of $45^{\circ}$ to be connected more effectively. The main member were constructed from three different wood species, Scotch pine, alder, beech and side members were constructed from $18 \mathrm{~mm}$-thick 9-ply furniture grade scotch pine plywood constructed in the laboratories of Karadeniz Technical University. SENCO staples with a crown width of $11,1 \mathrm{~mm}$ and leg length of $38,1 \mathrm{~mm}$ were used. $1,6 \mathrm{~mm}$ is the leg width and 1,4 $\mathrm{mm}$ is the thickness of staple which was covered with Sencote coating in order to not have rust.

\section{Experimental design}

\section{One stapled}

A complete one-factor experiment with 30 replications for each combination was carried out to check the factor effect on the resisting capacity of the joints against lateral shear loads. The factor was main members (Scotch pine-alder-beech) and therefore, totally 90 samples were loaded, and the results were recorded.

\section{One-row multi stapled}

Two-factor experiment with 10 replications for each combination was carried out to check the numbers of staple effect on the shear resistance of one row stapled wood joints. The factors were wood specie of main member (Scotch pine, alder, and beech) and the number of staples (2,3, and 4). Therefore, the numbers of joint tested in this part were 90 . The staple placement patterns based on the numbers of staple used are illustrated in Figure 3. All specimens were subjected a loading direction of parallel to staple alignment direction.

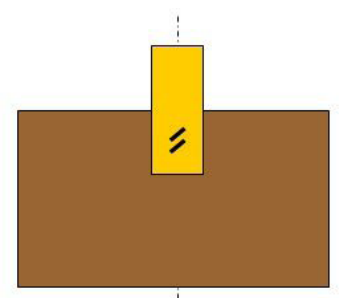

(a)

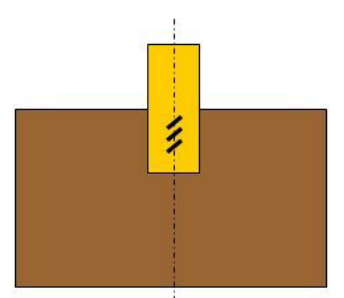

(b)

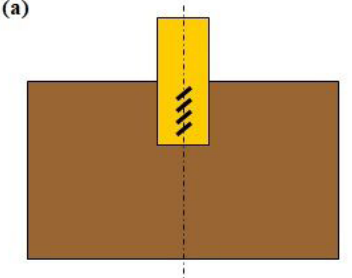

(c)

Figure 3: The staple placement pattern of three joint specimens connected with (a) two, (b) three, and (c) four one-row staples.

Moisture content (MC) and density of wood materials were determined based on the standard of ASTM D 4442 (2010) and ASTM D 2395 (2010), respectively. On the other hand, mechanical properties were measured based on the standard of ASTM D 1761 (2010).

\section{Joint preparing and testing}

Before joint preparation, all wood species and side members were rested in the chamber controlled at $20^{\circ} \mathrm{C}$ $\pm 5{ }^{\circ} \mathrm{C}$ temperature and $65 \% \pm 5 \%$ relative humidity. The staples were inserted into the joint members with a pneumatic staple gun at an air pressure of $483 \mathrm{KPa}$. All tests were carried out in the laboratory at $23{ }^{\circ} \mathrm{C} \pm 2{ }^{\circ} \mathrm{C}$ and $50 \% \pm 5 \%$ relative humidity. Figure 4 illustrates the testing machine to measure the shear force of stapled wood joints. All joint samples were loaded at $2,5 \mathrm{~mm} / \mathrm{min}$ on a MTS universal testing machine. Maximum shear loads and failure modes of tested joints were recorded. 


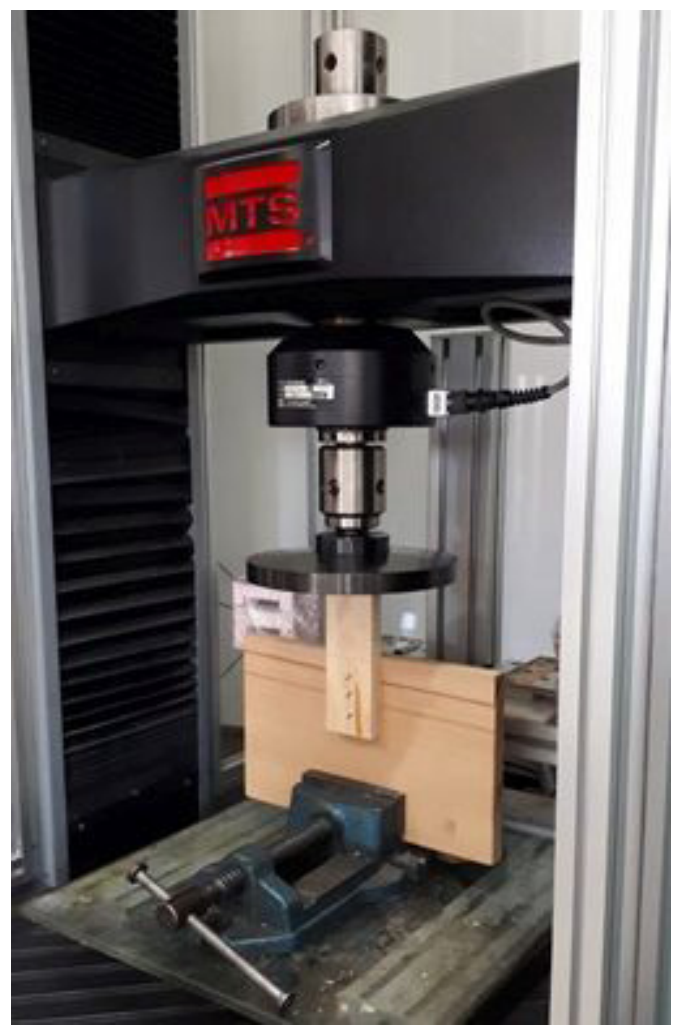

Figure 4: Test set-up for evaluating lateral shear load resistance of staple-connected wood joints.

\section{RESULTS AND DISCUSSIONS}

\section{Physical and mechanical properties}

Average density values of three wood species considered in this study were illustrated in Table 1 . The comparison of average density indicated that beech had a significantly greater density than the other wood species, followed by alder and Scotch pine. Likewise the average density of alder is significantly higher than that of Scotch pine as shown in Table 1.

Table 1: Average densities of wood species.

\begin{tabular}{|c|c|c|c|}
\hline & Scotch pine & Alder & Beech \\
\hline Density $\left(\mathrm{kg} / \mathrm{m}^{3}\right)$ & $450(\mathrm{C})(2)$ & $510(\mathrm{~B})(1)$ & $540(\mathrm{~A})(4)$ \\
\hline
\end{tabular}

Letters and numbers in parenthesis indicate statistical difference and coefficients of variation (COV), respectively.

\section{Comparison of average maximum shear loads}

\section{One stapled joints}

Table 2 listed the average maximum lateral shear loads with COV values of one stapled joints constructed from three different wood species. Each average value represents 30 sample replicates. In general, all of the one stapled joint samples failed in the mode of a failure in which the staple legs withdrew by bending out of the main member and both members were crushed due to releasing of staple legs. Figure 5 shows the failure 
mode for the one stapled wood joints. Table 2 shows average maximum load comparison of one-staple wood joints based on SAS analysis.

Table 2: The average maximum shears of one stapled wood joints.

\begin{tabular}{|c|c|c|c|}
\hline \multirow{2}{*}{ Maximum Load (N) } & \multicolumn{3}{|c|}{ Wood Specie } \\
\cline { 2 - 4 } & Scotch pine & Alder & Beech \\
\hline Average & $809(\mathrm{C})(13)$ & $1042(\mathrm{~B})(11)$ & $1233(\mathrm{~A})(8)$ \\
\hline
\end{tabular}

Letters and numbers in parenthesis indicate statistical difference and coefficients of variation (COV), respectively.

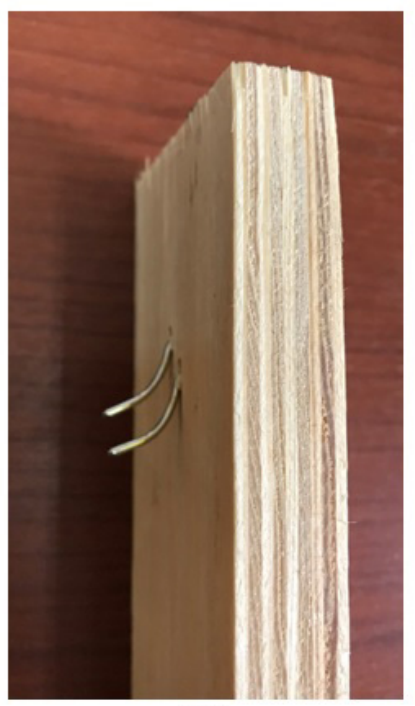

(a)

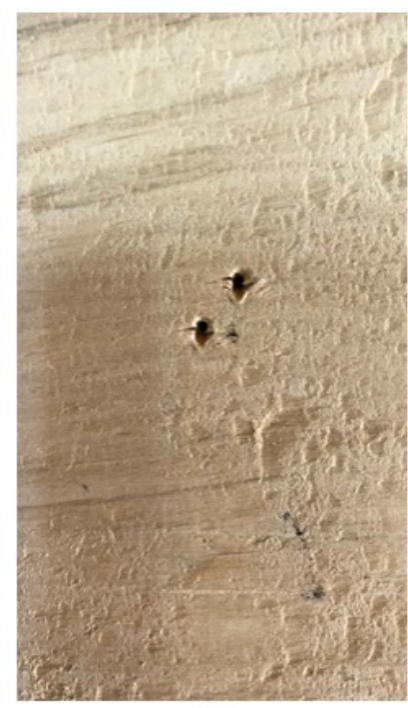

(b)

Figure 5: Failure mode of one-staple wood joints; (a) staple legs bent; (b) materials crushed in the side member.

As shown in Table 2, the average maximum shear force of one stapled beech joint is significantly greater than the ones of one stapled alder and Scotch pine joints, and this order significantly followed by one stapled alder joints and Scotch pine joints. Demirel et al. (2013) revealed the similar trend among three different OSB joints. In that study, the average maximum shear of one stapled joint in OBS-III was significantly higher than the ones of one stapled joints in OSB-type-II and OSB-type-I, and this order significantly followed by the one stapled joints in OSB-type-II and OSB-type-I.

\section{One-row multi stapled joints.}

Table 3 listed the average maximum shear loads with COV values of one-row multi stapled joints constructed from three different wood species. Each value stands for an average of 10 results. Most of the joints indicated a failure mode of the staple legs withdrew by bending out of the main member and both members were crushed due to releasing of staple legs, which is a similar failure mode of one stapled joints. Additionally, five joints indicated a failure mode of shearing among the layers of side members. Figure 6 shows the failure mode for one-row multi stapled wood joints. 


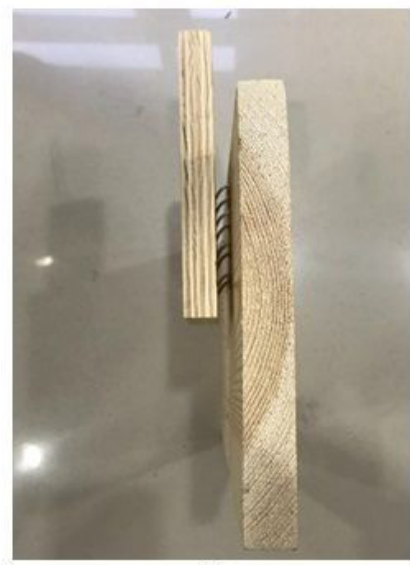

(a)

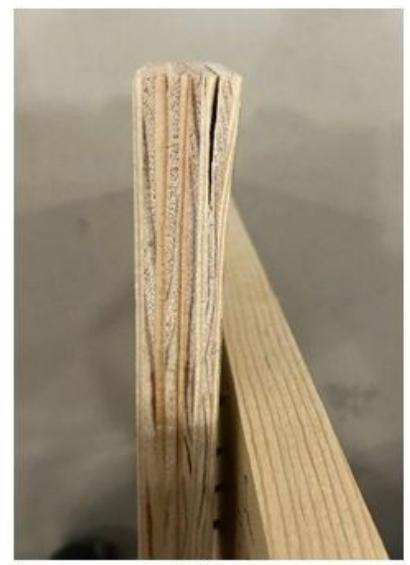

(b)

Figure 6: Showing the failure modes of one-row multi-staple joints; (a) Staple leg withdrawing; (b) Shearing among plywood layers.

ANOVA model was applied to check main effects and the interaction effects on average maximum shear loads. Results showed that the statistical interaction between the wood species and the numbers of staple was less than $0,05(0,038)$ and this interaction was significant. Table 3 and Table 4 listed the average maximum shear values of one-row multi stapled joints according to the wood specie and numbers of staple, respectively. The results of the statistical analysis yielded 9 treatments combinations. Statistical differences were compared by the average LSD value of $279 \mathrm{~N}$ with the results of the multiple comparison procedure, which was maintained at 5 percent significance level.

As shown in Table 3, a statistical difference is available among the average lateral shear values of onerow joints obtained from three different wood materials. Accordingly, the average shear values of the one-row multi-staple joints manufactured from beech wood are statistically greater than those obtained from other wood species. The average lateral shear values of the joints connected with 2, 3 and 4 staples using the alder wood were significantly lower than those manufactured from beech wood and significantly greater than those manufactured from Scotch pine.

Table 3: Average comparisons of maximum lateral shear loads of one-row multi-stapled joints for wood specie within each of numbers of staple.

\begin{tabular}{|c|c|c|c|}
\hline \multirow{2}{*}{ Number of Staple } & \multicolumn{3}{|c|}{ Wood Specie } \\
\cline { 2 - 4 } & Scotch pine & Alder & Beech \\
\hline 2 & 1721 (B) (8) & 2027 (B) (12) & $2562(\mathrm{~A})(13)$ \\
\hline 3 & 2602 (C) (8) & 3305 (B) (14) & $3632(\mathrm{~A})(8)$ \\
\hline 4 & 3498 (C) (10) & 4487 (B) (10) & 4893 (A) (11) \\
\hline
\end{tabular}

Letters and numbers in parenthesis indicate statistical difference and coefficients of variation (COV), respectively.

There was only no significant difference between the average strength values of the joints connected with 2 staples using alder and Scotch pine. Beech joints, which have the highest density, showed the highest average shear force values compared to the ones manufactured from alder and Scotch pine, while Scotch pine joints, which has the lowest density, indicated the lowest force. These differences in average shear force could be based on the difference in the density of wood specie. Likewise, Demirel (2012) studied the shear force of onerow multi-staple OSB joints and used three OSB materials whose densities were different from one another. OSB-type-III had the highest density among the others, and this was significantly pursued by OSB-type-II and OSB-type-I. Results showed that the average maximum force values of the joints manufactured from OSBtype-III and OSB-type-II were higher than those manufactured from OSB-type-I. The reason of this result was 
indicated as the sensitivity of the OSB resistance to the medium layer density of the OSB material. The results in current study are consistent with above previous study.

Table 4: Average comparisons of maximum lateral shear loads of one-row multi-stapled joints for numbers of staple within each of wood specie.

\begin{tabular}{|c|c|c|c|}
\hline \multirow{2}{*}{ Wood Specie } & \multicolumn{3}{|c|}{ Number of Staple } \\
\cline { 2 - 4 } & $\mathbf{2}$ & $\mathbf{3}$ & $\mathbf{4}$ \\
\hline Scotch pine & $1721(\mathrm{C})(8)$ & $2602(\mathrm{~B})(8)$ & $3498(\mathrm{~A})(10)$ \\
\hline Alder & $2027(\mathrm{C})(12)$ & $3305(\mathrm{~B})(14)$ & $4487(\mathrm{~A})(10)$ \\
\hline Beech & $2562(\mathrm{C})(13)$ & $3632(\mathrm{~B})(8)$ & $4893(\mathrm{~A})(11)$ \\
\hline
\end{tabular}

Letters and numbers in parenthesis indicate statistical difference and coefficients of variation (COV), respectively.

Table 4 indicated that the average maximum shear values of one-row 4 staples joints manufactured from beech, alder, and Scotch pine were statistically greater than the ones of the one-row joints with 3 and 2 staples. Similarly, this order was significantly followed by the average maximum shear values of the one-row 3 staples joints and 2 staples joints. Demirel et al. (2013) observed that the average maximum shear values of one-row multi-staple joints manufactured from three different OSB materials increased by increasing the staple number from 2 to 4 with one increment. These results are also consistent with the result in current study.

\section{Inspection of displacement}

Table 5 indicates the displacement rates of the one-row vertically aligned multi-staple wood joints. As seen in the table, for the joints with 2 staples, changing the wood specie from Scotch pine with lower density to alder and beech with higher density yielded higher displacement value. Additionally, the joint with lower maximum shear load such as Scotch pine joints yielded less displacement value compared to the ones with higher maximum shear load. The same relation is valid for the joints connected with 3 and 4 staples.

Additionally, through down in the columns of Table 1, increasing staple number increased the displacement value. Therefore, it can be said that displacement values acted similar to shear behavior of the joints.

Table 5: Displacement of the one-row multi-staple joints constructed from Scotch pine, alder, and beech wood.

\begin{tabular}{|c|c|c|c|c|}
\hline \multirow{2}{*}{ Displacement (cm) } & \multicolumn{3}{c|}{ Wood Specie } \\
\cline { 3 - 5 } \multicolumn{2}{|c|}{} & Scotch pine & Alder & Beech \\
\hline \multirow{2}{*}{$\begin{array}{c}\text { Number } \\
\text { of Staples }\end{array}$} & 2 & $0,17(5)$ & $0,19(4)$ & $0,22(4)$ \\
\cline { 2 - 5 } & 3 & $0,20(6)$ & $0,24(6)$ & $0,27(6)$ \\
\cline { 2 - 5 } & 4 & $0,24(9)$ & $0,25(6)$ & $0,27(6)$ \\
\hline
\end{tabular}

Numbers in parenthesis indicate standard deviation values.

\section{Prediction equations}

In order to determine the effect of the numbers of staple on the force of one-row multi-stapled joints constructed from three different wood species, the least squares method was used to fit tested joint data for each of three wood species by following prediction Equation 1.

$$
P_{N}=K \times N^{a}
$$


Where:

$P_{N}$ denotes estimated average maximum shear load of one-row multi-stapled joints $(\mathrm{N})$,

$N$ denotes the numbers of staple, $K$ and $a$ denote regression constants.

Table 6 gives some values based on regression in order to determine the prediction equation. As seen in Table $6, \mathrm{~K}$ values were quite similar to the average maximum shear loads of one stapled joints, $F_{O}$, for each wood specie. Therefore the regression constants of 806, 1028, and $1235(\mathrm{~K})$ in the Equation 1 were substituted with their corresponding one stapled lateral loads of 809,1043 , and $1233\left(F_{O}\right)$, respectively. This replacement let to have the following Equation 2.

$$
P_{N}=F_{O} \times N^{1,03} \quad\left(r^{2}=0,97\right)
$$

Where:

$F_{O}$ denotes the average maximum shear load of one stapled joints constructed from three different wood species $(\mathrm{N})$.

Table 6: Constants, $\mathrm{r}^{2}$ and $\mathrm{P}$ values for prediction equations for predicting average maximum resistance loads of one-row multi stapled joints constructed from three different wood species.

\begin{tabular}{|c|c|c|c|c|c|c|}
\hline Wood specie & $\mathbf{K}$ & $\mathbf{a}$ & $\mathbf{r}$-square & $\mathbf{p}$ value & $\boldsymbol{F}_{\boldsymbol{O}}$ & $\mathbf{K} / \boldsymbol{F}_{\boldsymbol{O}}$ \\
\hline Scotch pine & 806 & 1,06 & 0,97 & $<0,0001$ & 809 & 1,00 \\
\hline Alder & 1028 & 1,05 & 0,97 & $<0,0001$ & 1043 & 0,99 \\
\hline Beech & 1235 & 0,99 & 0,97 & $<0,0001$ & 1233 & 1,00 \\
\hline
\end{tabular}

At the end of regression analysis, a common correction factor was determined as $\mathrm{N}^{1,03}$ in order to check the multi-staple additive effects. The factor, $\mathrm{N}^{1,03}$, was quite similar to the correction factor $\left(\mathrm{N}^{0,92}\right)$ derived from the study of one stapled joint constructed from OSB materials (Demirel et al. 2013) and the correction factor (N ${ }^{0,95}$ ) derived from the study of one stapled joint in pine plywood (Zhang and Maupin 2004).

In order to determine the effects of the numbers of staple and wood density on the shear load of one-row multi stapled joints constructed from three wood specie, the following prediction equation was adapted to the each tested joint data constructed from all three wood species including one stapled joints Equation 3:

$$
P_{N}=K_{2} \times D^{b} \times N^{c}
$$

Where:

$D$ denotes wood density $\left(\mathrm{kg} / \mathrm{m}^{3}\right)$,

$K_{2}, b$, and $c$ denotes regression constants,

$N$ denotes the numbers of staple.

At the end of regression analyses, the regression constants, $\mathrm{K}_{2}, \mathrm{~b}, \mathrm{c}, \mathrm{r}^{2}$, the values were determined as 4490 , $2,15,1,03,0,97$, respectively. Table 7 listed predicted, observed and comparisons of average maximum shear strength of one-row multi-staple wood joints. 
Table 7: Comparison of estimated maximum shear loads of one-row multi stapled wood joints using Equation 2 and Equation 3 with observed values.

\begin{tabular}{|c|c|c|c|c|c|c|c|}
\hline \multicolumn{4}{|c}{} & \multicolumn{2}{c|}{$\begin{array}{c}\text { Predicted } \\
\text { Maximum Load }\end{array}$} & \multicolumn{2}{c|}{ Ratio } \\
\hline Wood Specie & $\begin{array}{c}\boldsymbol{D} \\
\left(\mathrm{kg} / \mathrm{m}^{3}\right)\end{array}$ & $\boldsymbol{N}$ & Obs. (N) & $\mathbf{F . 2}$ & $\mathbf{F . 3}$ & $\begin{array}{c}\text { F. 2/ } \\
\text { Obs. }\end{array}$ & $\begin{array}{c}\text { F. 3/ } \\
\text { Obs. }\end{array}$ \\
\hline \multirow{4}{*}{ Scotch pine } & 450 & 1 & 809,09 & 809,09 & 806,59 & $\mathbf{1}$ & $\mathbf{1}$ \\
\cline { 2 - 9 } & 450 & 2 & 1720,96 & 1652 & 1647,08 & $\mathbf{0 , 9 6}$ & $\mathbf{0 , 9 6}$ \\
\cline { 2 - 9 } & 450 & 3 & 2601,53 & 2508,32 & 2500,85 & $\mathbf{0 , 9 6}$ & $\mathbf{0 , 9 6}$ \\
\cline { 2 - 9 } & 450 & 4 & 3498,15 & 3373,42 & 3363,37 & $\mathbf{0 , 9 6}$ & $\mathbf{0 , 9 6}$ \\
\hline \multirow{4}{*}{ Alder } & 510 & 1 & 1043,02 & 1043,02 & 1055,66 & $\mathbf{1}$ & $\mathbf{1 , 0 1}$ \\
\cline { 2 - 8 } & 510 & 2 & 2026,86 & 2129,83 & 2155,67 & $\mathbf{1 , 0 5}$ & $\mathbf{1 , 0 6}$ \\
\cline { 2 - 8 } & 510 & 3 & 3304,57 & 3233,85 & 3273,08 & $\mathbf{0 , 9 8}$ & $\mathbf{0 , 9 9}$ \\
\cline { 2 - 8 } & 510 & 4 & 4487,02 & 4349,17 & 4401,94 & $\mathbf{0 , 9 7}$ & $\mathbf{0 , 9 8}$ \\
\hline \multirow{5}{*}{ Beech } & 540 & 1 & 1233,43 & 1233,43 & 1193,69 & $\mathbf{1}$ & $\mathbf{0 , 9 7}$ \\
\cline { 2 - 8 } & 540 & 2 & 2562,16 & 2517,82 & 2437,55 & $\mathbf{0 , 9 8}$ & $\mathbf{0 , 9 5}$ \\
\cline { 2 - 8 } & 540 & 3 & 3632,46 & 3822,94 & 3701,07 & $\mathbf{1 , 0 5}$ & $\mathbf{1 , 0 2}$ \\
\cline { 2 - 7 } & 540 & 4 & 4893,39 & 5141,44 & 4977,54 & $\mathbf{1 , 0 5}$ & $\mathbf{1 , 0 2}$ \\
\hline
\end{tabular}

$D=$ density of wood species $\left(\mathrm{kg} / \mathrm{m}^{3}\right) ; N=$ numbers of staple; Obs. = observed load values $\mathrm{N}, \mathrm{F} .=$ equation.

As shown in Table 7, the ratios of predicted and observed values of multi stapled wood joint are ranked between 0,95-1,05 and mostly around 1 . This indicates that Equation 2 is capable to predict the lateral shear load of one-row multi stapled joints constructed from three wood species. Likewise Equation 3 is also capable for estimating the shear load of the wood joints as long as the wood density is known. Therefore, using the prediction Equation 2 and Equation 3 to predict average maximum shear force of one-row multi stapled joints is remarkable.

\section{CONCLUSIONS}

Shear force of one stapled and one-row multi stapled joints constructed from Scotch pine, alder and beech were investigated. Results of the study revealed that wood density had a statically significant effect on the shear force of one stapled joints. The staple holding resistance of one stapled joints constructed from beech with a higher density of $540 \mathrm{~kg} / \mathrm{m}^{3}$ was significantly $191 \mathrm{~N}$ greater than that of one stapled joints constructed from alder with a density of $510 \mathrm{~kg} / \mathrm{m}^{3}$ and significantly $424 \mathrm{~N}$ greater than that of the one stapled joints constructed from Scotch pine with the lowest density $450 \mathrm{~kg} / \mathrm{m}^{3}$. Likewise, the staple holding resistances of one stapled alder joints was significantly $233 \mathrm{~N}$ greater than that of one stapled Scotch pine joints.

The results of the experimental study indicated that increasing numbers of staple from one to four increased the shear force of one-row multi stapled wood joints. One-row multi stapled joints constructed from beech had significantly greater average maximum shear force than the ones of constructed from alder and Scotch pine. Likewise one-row multi stapled joints constructed from alder had significantly greater average maximum shear force than the one of constructed from Scotch pine. The staple holding capacity of the wood joints is based on wood density because the higher density wood joint yielded greater lateral shear force.

The wood joints with higher density and the joints with higher staple number also yielded higher displacement value. Displacement values acted similar to maximum strength of the wood joints.

Prediction equations derived by regression analysis yielded very close numbers to the laboratory tests results. Therefore, the force of one-row multi stapled wood joints can be nearly estimated by two prediction equations. However, the shear load of one stapled wood joints needed to be known for Equation 2 and wood density is needed to be known for Equation 3.

Previous studies made investigation on the shear of one stapled and multi staple joints in OSB and ply- 
wood materials. A study on the shear force of the one stapled and multi-staple wood joints was missing. Therefore, this study is part of completing the data on the shear of stapled joints constructed from wood and wood based material. Since beech, alder, and Scotch pine are mostly used wood species in furniture field both in Turkey and around the world, these wood species were evaluated in this study. The results of the current study are perfectly consistent with previous studies on shear of stapled joints.

\section{REFERENCES}

ASTM. 2010. Standard test method for mechanical fasteners in wood. American Society for Testing and Materials. ASTM D 1761. 2010. ASTM International: West Conshohocken, PA, USA. https://www.astm.org/ Standards/D1761.htm

ASTM. 2010. Standard test methods for specific gravity of wood and wood-base materials. ASTM D 2395. 2010. ASTM International:West Conshohocken, PA, USA. https://www.astm.org/Standards/D2395.htm

ASTM. 2010. Standard Test Methods for Direct Moisture Content Measurement of Wood and Wood-Base Materials. ASTM D 4442. 2010. ASTM International: West Conshohocken, PA, USA. https://www.astm.org/ Standards/D4442.htm

Dai, L.; Zhang, J.; Quinn, F. 2008. Lateral and tensile resistances of glued face-to-face and end-to-face joints in pine plywood and oriented strandboards. For Prod $J$ 58(3): 50-54. http://kb.forestprod.org/Main/ ind/?id $=73654$

Demirel, S. 2012. Static and fatigue performance of oriented strandboard as upholstered furniture frame stock. Mississippi State University, Starkville, USA. http://sun.library.msstate.edu/ETD-db/theses/available/ etd-03212012-085200/unrestricted/Final.pdf

Demirel, S.; Zhang, J. 2014. Face lateral resistance of oriented strandboard joints connected with two rows of 16-gauge coated staples. Wood Fiber Sci 46(2): 280-290. https://wfs.swst.org/index.php/wfs/article/ view/898

Demirel, S.; Tor, O.; Yu, X.; Zhang, J. 2018. Lateral loads of stapled glued surface-to-surface joints in oriented strandboard for furniture. Wood Fiber Sci 50(3): 280-290. https://dx.doi.org/10.22382/wfs-2018-028

Demirel, S.; Zhang, J.; Jones, D.; Kitchens, S.; Martin, W.V.; Yu, H. 2013. Face lateral shear resistance of one-row multistaple joints in oriented strandboard. For Prod J 63(5-6): 207-212. https://dx.doi. org/10.13073/FPJ-D-12-00073

Erdil, Y.Z.; Zhang, J.; Eckelman, C.A. 2003. Staple holding strength of furniture frame joints constructed of plywood and oriented strandboard. For Prod J 53(1): 70-75. http://kb.forestprod.org/Main/ind/?id=66937

General Service Administration. GSA. 1998. SA FNAE-80-214A: Upholstered furniture test method. General Services Administration. Washington, D.C., USA. https://www.gsa.gov/cdnstatic/Upholstered_Furniture_Test_Method.pdf

Yadama, V.; Zhang, J.; Syed, B.M.; Steele, P. 2002. Experimental analysis of multiple staple joints in selected wood and wood-based materials. J Test Eval 30(5): 400-407. https://dx.doi.org/10.1520/JTE12330J

Zhang, J.; Quin, F.; Tackett, B.; Park, S.H. 2002a. Direct withdrawal strength of single-staple joints in pine plywood. For Prod J 52(2): 86-91. http://kb.forestprod.org/Main/ind/?id=66828

Zhang, J.; Quin, F.; Tactkett, B. 2002b. Direct withdrawal strength of multi-staple joints in pine plywood. For Prod J 52(5): 61-66. http://kb.forestprod.org/Main/ind/?id=66858

Zhang, J.; Maupin, M. 2004. Face lateral and withdrawal resistances of staple joints in furniture-grade pine plywood. For Prod J 54(6): 40-46. http://kb.forestprod.org/Main/ind/?id=67119

Zhang, J.; Han, N.; Maupin, M. 2006. Lateral edge resistance of single-fastener furniture joints in wood-based panel products. For Prod J 56(2): 33-39. http://kb.forestprod.org/Main/ind/?id=67921 